\title{
Mutual information: a measure of dependency for nonlinear time series
}

\author{
Andreia Dionisio $^{\mathrm{a}, *}$, Rui Menezes ${ }^{\mathrm{b}}$, Diana A. Mendes ${ }^{\mathrm{b}}$ \\ ${ }^{a}$ Management Department, University of Evora, Largo dos Colegiais, 2, 7000, Evora, Portugal \\ ${ }^{\mathrm{b}}$ ISCTE, Av. Forcas Armadas, 1649-025 Lisboa, Portugal
}

Received 27 November 2003

Available online 20 July 2004

\begin{abstract}
The main goal of the paper is to show how mutual information can be used as a measure of dependence in financial time series. One major advantage of this approach resides precisely in its ability to account for nonlinear dependencies with no need to specify a theoretical probability distribution or use of a mean-variance model.

(C) 2004 Elsevier B.V. All rights reserved.
\end{abstract}

PACS: $89.70 .+\mathrm{c} ; 89.90 .+\mathrm{n}$

Keywords: Mutual information; Nonlinear dependence; Efficient market hypothesis

\section{Introduction}

The most known measure of dependence between two random variables is the coefficient of linear correlation, but its application requires a pure linear relationship, or at least a linear transformed relationship (see e.g. Refs. [1,2]), because it is nothing but a normalized covariance and only accounts for linear relationships. However, this statistics may not be helpful in determining serial dependence if there is some kind of nonlinearity in the data. In this context, it seems that a measure of

\footnotetext{
*Corresponding author. Tel.: + 351-91-910-8039; fax: + 351-266-742494.

E-mail address: andreia@uevora.pt (A. Dionisio).
} 